\title{
Influence of kinship on helping behavior in Galápagos mockingbirds
}

\author{
Robert L. Curry * \\ Department of Biology, The University of Michigan, Ann Arbor, MI 48109-1048, USA \\ Received April 25, 1987/Accepted October 10, 1987
}

Summary. The social organization of the Galapagos mockingbird (Nesomimus parvulus) is unusual in that groups frequently include more than one breeding pair (plural breeding), and helping behavior is flexible: some birds neither breed nor help, while others do both. To investigate the influence of kinship on helping behavior, I categorized each bird as a helper or non-helper with respect to each nest within its group where it had an opportunity to help. The incidence of helping varied with relatedness: more birds helped when nestlings available to be fed were close relatives than when not. This result was independent of a higher incidence of helping among males than among females and of variation with age among males. Proportionally more nonbreeding than breeding males helped, but breeding and nonbreeding females helped equally infrequently; breeders helped most often after their own nests failed. The incidence of helping was highest among birds with opportunities to feed offspring of breeders that had fed the potential helper as a nestling, suggesting a mechanism for kin discrimination based on associative learning. Juveniles with opportunities to choose among alternative recipients preferentially fed closely related nestlings, but insufficient information was available to determine if adults also did so. Kinship did not influence the rate at which nestlings were fed by helpers. Juveniles fed nestlings at lower rates than did adult helpers, but helping effort was otherwise unaffected by age, sex, or relatedness. Limitation of help to former feeders functions as a mechanism for directing aid to relatives in a plural breeding system where degrees of kinship vary among potential recipients within the same group.

* Present address: Archbold Biological Station, Lake Placid, FL 33852, USA

\section{Introduction}

Helpers in cooperatively breeding birds are typically close relatives of the recipients of their aid (Brown 1978, 1987; Emlen 1978, 1984). For this reason, kin selection (Maynard Smith 1964) has been cited frequently as a mechanism that could account for the evolution of helping behavior (e.g. Brown 1974, 1978; Ricklefs 1975; Emlen 1978, 1984; Reyer 1980, 1984; Clarke 1984; Rabenold 1985): individuals that help may improve their inclusive fitness (Hamilton 1964) if their indirect fitness (Brown 1980; Brown and Brown 1981a) is augmented by assisting in the production of nondescendent relatives.

The fact that most helpers are closely related to the recipients of their aid, however, does not by itself indicate that the indirect component of inclusive fitness has been important in the evolution of helping behavior. Even if the reproductive success of helped pairs is substantially increased over that of unaided pairs, as it often is (Brown 1978; Emlen 1978, 1984; Brown et al. 1982; Rabenold 1984; Reyer 1984), direct benefits to helpers in theory could be even more important. Direct benefits have been hypothesized to accrue as a consequence of helping behavior through increased chances of breeding following territory expansion (Woolfenden and Fitzpatrick 1978), through increased chances of mating (Reyer 1984), or through social reciprocation from breeders or nestlings (Brown 1978, 1983, 1987; Ligon and Ligon 1978, 1983; Brown and Brown 1980; Ligon 1983; Emlen 1984; Caraco and Brown 1986). Several studies have attempted to estimate the relative importance of direct and indirect effects of helping behavior on the fitness of donors (e.g. Vehrencamp 1979; Rowley 1981; Reyer 1984; Woolfenden and 
Fitzpatrick 1984; Rabenold 1985 ; Curry 1987), but no consensus has emerged.

One way to discriminate among these hypothetical mechanisms for the maintenance of helping behavior is to examine factors influencing who gives help, how much, and to whom. If helping is maintained through indirect fitness benefits, correlations between helping behavior and relatedness should be apparent: helpers should differentially contribute aid to close relatives (Hamilton 1964; Harvey 1980). Differential treatment of kin could be exhibited in at least three ways. First, if two or more individuals are available to receive help, helpers could aid closer relatives preferentially. Second, even when alternative recipients are not available, the probability that individuals give aid could be higher when they interact with close relatives than when interacting with more distantlyrelated individuals or with nonrelatives. Third, helpers could donate aid in proportion to their degree of relatedness to the young they feed. Helping behavior that followed any or all of these patterns would constitute kin discrimination (Holmes and Sherman 1983) or kin-directed behavior (Byers and Beckoff 1986) and would support the hypothesis that indirect fitness gains through effects on nondescendent relatives have been important in the evolution of helping. Alternative hypotheses postulating that direct benefits are crucial for the evolution and maintenance of helping behavior do not necessarily predict kin-directed helping, because direct benefits would accrue to helpers whether or not they were related to the recipients.

Discrimination between kin and nonkin by potential helpers has been studied rarely for two reasons. First, in most territorial cooperative breeders studied to date, groups contain only one breeding pair (singular breeding; Brown 1978), making choices unavailable; a bird can choose to help or not to help, but it cannot make choices between two sets of breeders, one related and one not, without leaving the territory. It has also been assumed that all nonbreeders actively help in most singularly-breeding species, making direct evaluation of factors affecting helping behavior difficult because no non-helpers exist that can be compared with helpers (Rabenold 1985; for an example where incidence of helping by nonbreeders does vary, possibly as a function of kinship, see Lewis $1982 \mathrm{a}, \mathrm{b})$. Second, the case in which potential helpers do have choices among different sets of breeders has only recently been studied. Helpers in several colonial species preferentially aid close relatives in situations where, because territories are not maintained at breeding colonies, alternative re- cipients are clearly present (Reyer 1980, 1984; unpublished studies by Emlen and Wrege and by Avery and Krebs, reviewed in Brown 1987).

Potential helpers may also have choices among recipients that differ in relatedness in territorial species where groups include two or more breeding pairs that maintain separate nests (plural breeding, Brown 1978). However, whether helping behavior is influenced by kinship in plurally-breeding territorial species has been addressed in only two previous studies, both of which found preliminary evidence for differential treatment of kin (Clarke 1984; Glen 1985). The purpose of this paper is to investigate the influence of kinship on helping behavior in the Galápagos mockingbird (Nesomimus parvulus), another territorial species with plural groups and separate nesting (Curry 1988). Along with plural group structure, the flexibility of helping behavior in this species facilitates study of the relationship between kinship and helping. Both male and female mockingbirds can help as juveniles, as nonbreeding adults, or as breeding adults aiding other pairs in the same group; not all birds help at all available nests, and some neither breed nor help. This variation makes it possible to look for differences between birds that help and birds that do not.

Galápagos mockingbirds help primarily by delivering food to nestlings and fledged young (Grant and Grant 1979; Kinnaird and Grant 1982; Curry 1987). Here I focus on two aspects of helping during this phase of reproduction. First, I consider whether kinship influences the proportion of birds that help when given opportunities to do so. Second, I ask whether relatedness influences the effort expended by helpers in feeding nestlings. For each analysis, I also consider the potentially confounding effects of sex, age, and breeding status, which are known to influence helping behavior in some other systems (e.g. Stallcup and Woolfenden 1978). Grant and Grant (1979) and Kinnaird and Grant (1982) found that at least some mockingbird helpers on Genovesa aided their parents, but they did not investigate the possibility that helpers aid close kin in preference to other possible recipients because the plural breeding structure was not recognized.

\section{Methods}

Mockingbirds were studied on Genovesa, an isolated island $17.4 \mathrm{~km}^{2}$ in area in the NE corner of the Galapagos Archipelago, beginning in 1978 (Grant and Grant 1979). Description of the island and study area are given in Grant and Grant (1980) and Kinnaird and Grant (1982). I studied the population for one to six months between January and June in each year, 
1981-84, in an area of up to 50 ha. Additional intensive observations were made by M.F. Kinnaird in 1980 and by P.R. Grant and coworkers between June and August in most years and between January and April in 1984 and 1985. Nesting took place during a wet season lasting up to three months between January and April in each year, 1978-82. El Niño conditions produced an extended breeding season between December 1982 and July 1983, during which some pairs nested six times; pairs normally produced one to three broods (Grant and Grant 1979; Curry 1985, 1987). In 1984, only eight pairs in the study area nested following a brief rainy period, and none nested during a drought in 1985.

Adult and juvenile mockingbirds were captured in mist nets or traps and were weighed, measured, and banded with unique combinations of plastic color bands and, from 1982 onwards, a numbered aluminum band. Nestlings were banded before fledging. Birds classified as juveniles were in juvenal or immature plumage and were up to six months old. All birds were classified as adults after their first January, when they were at least seven months old and were in adult plumage. Sex was determined from measurements of the length of the wing as in Kinnaird and Grant (1982).

To examine the frequency of helping and preferences among recipients, $I$ considered all birds living in groups whose breeding activities were intensively studied between 1980 and 1984; group membership was incompletely known in 1978 and 1979. The sample includes 16 groups in 1980, 36 in 1981, 38 in 1982, 25 in 1983, and seven in 1984, totalling 122 groupyears. (Another 19 groups studied in 1984 were excluded as none of their members nested.) I defined group membership on the basis of the movements and activities of dominant males, which defend territories inhabited by one to 11 additional birds; during each season up to three pairs nested, often simultaneously, within each group territory (Curry 1988).

Observers found most nests during nest-building or incubation, and monitored subsequent activity through the entire nestling period. A single female laid and incubated eggs in each nest, except for three nests where two females contributed eggs; these nests are excluded from the analyses below. Each breeding female was conspicuously paired with one mate, classified as the parental male; breeding males aided in nest building and defense, guarded females prior to laying, and fed nestlings. I classified birds as helpers with respect to nests where they fed nestlings other than their own, and I categorized birds as nonhelpers for each nest in their groups where they were not parents and did not not feed the nestlings. Nests where eggs failed to hatch or where nestlings were taken by predators shortly after hatching were excluded since actual feeding was not observed.

Helping classifications were made, and feeding rates by breeders and helpers measured, on the basis of 639 observation samples (nest-watches) at 220 nests with nestlings. When possible, $1 \mathrm{~h}$ watches were conducted at three-day intervals at each nest from the second to the 11th or 12th day after hatching. Date, time of day, and number of chicks in the nest were recorded for each watch. Each nest was watched an average of three times $( \pm 1.8 \mathrm{SD}$, range $=1-12)$, for an average total of $152 \mathrm{~min}( \pm 110.1 \mathrm{SD}$, range $=15-705 \mathrm{~min})$. A feeding visit was scored whenever a bird delivered food to nestlings, either directly or by feeding an incubating female who then fed the nestlings. Galápagos mockingbirds have little fear of humans, so observers usually watched nests from less than $5 \mathrm{~m}$ away. The bird bringing food was identified for nearly all $(98 \%)$ feeding visits. Helpers accounted for 920 of the 5776 feeding visits recorded. Feeding rates (feeding visits/h) were calculated for each attendant during each watch. I scored the relative size of food items fed to nestlings as small, medium, or large; I found no evidence for any systematic variation in the type or size of food brought by different birds, so here I consider all feeding visits equally. Each bird classified as a helper was seen feeding an average of 9 times $( \pm 11.2 \mathrm{SD}$, range $=1-60, n=114)$

In the analyses below, each case in which a bird had an opportunity to feed nestlings not its own at one or more nests of a pair in the same group in a particular year is defined as a helper-season. I refer to nestlings available to be fed as potential recipients, and to birds with helping opportunities as potential helpers; each potential helper was scored either as a helper or non-helper. All resident adults were considered to be potential helpers at nests in their groups. Juveniles were considered as potential helpers only if they were at least one month old because younger juveniles never helped. I exclude juveniles that immigrated into the study area while breeding was in progress in 1983 (Curry 1985). Most joined groups of nonrelatives, but none helped, and their inclusion would bias the results in favor of a hypothesis of kin-preference.

Helper and non-helper classifications are assumed to apply to each complete breeding attempt. Birds classified as non-helpers based on nest-watch data were virtually never seen either feeding nestlings during casual observations nor feeding fledglings later. Between 1980 and 1984, fledglings were seen being fed by identifiable birds 791 times. Of these, $88 \%$ of fledgling feedings were by a parent, and $11 \%$ by a bird that had been previously recorded as a nest helper. Birds other than nest attendants (parent or helper) fed fledglings only twice $(0.3 \%$ of observations); in both cases the fledgling was fed off its natal territory by a member of another group.

Relatedness between potential helpers and recipients was calculated from pedigree information compiled since 1978. In most cases classification of helper-recipient relatedness was based on the parentage of the helper. Cases where females of known parentage $(n=21)$ changed groups and bred are also included; I assumed that birds resident in a group when a female immigrated were unrelated to her. This assumption was violated in only one of 12 cases where complete information was available, when a female rejoined her natal group after breeding in an adjacent group for four years. Actual relatedness values may differ from estimated relatedness if birds classifed as breeders were not biological parents. In this population, discrepancies of this kind are likely to arise occasionally, as a result of extra-pair copulations involving dominant males and subordinate females (Curry 1988).

Categorical data were analyzed using log-likelihood ratio tests of association ( $G$-tests) except where empty cells necessitated use of Chi-square tests. Test statistics $(G)$ are modified by William's adjustment where appropriate (Sokal and Rohlf 1981).

\section{Results}

\section{Factors influencing the incidence of helping}

1. Effects of age and sex of potential helper. In most years the majority of birds that helped were young males (Table 1). Prior to 1983, 99\% of helpers were males, but $41 \%$ of birds that helped in 1983 and 1984 were females. For 1978-84 combined, $90 \%$ of birds that helped one or more times were males. The sex ratio of helpers was nearly the same ( $89 \%$ males) if each helper is counted once for each different nest at which it helped $(n=$ 
Table 1. Age and sex of helpers. Each bird is listed once for each year in which it helped at one or more nests

\begin{tabular}{|c|c|c|c|c|c|c|c|c|c|c|c|c|}
\hline \multirow[t]{2}{*}{ Helper age ${ }^{a}$} & \multicolumn{2}{|c|}{ 1978-1980 } & \multicolumn{2}{|c|}{1981} & \multicolumn{2}{|c|}{1982} & \multicolumn{2}{|c|}{1983} & \multicolumn{2}{|c|}{1984} & \multicolumn{2}{|c|}{$1978-1984$} \\
\hline & M & $\mathrm{F}$ & M & $F$ & M & $\mathrm{F}$ & M & $\mathrm{F}$ & M & $\mathrm{F}$ & $\mathrm{M}$ & $\mathrm{F}$ \\
\hline Juvenile & 6 & 0 & 0 & 0 & 0 & 0 & 5 & 5 & 0 & 0 & 11 & 5 \\
\hline $1 \mathrm{yr}$ & 8 & 0 & 3 & 0 & 2 & 0 & 1 & 1 & 0 & 1 & 14 & 2 \\
\hline $2 \mathrm{yr}$ & 4 & 0 & 4 & 0 & 3 & 0 & 0 & 0 & 0 & 0 & 11 & 0 \\
\hline $3 \mathrm{yr}$ & - & - & 4 & 0 & 5 & 0 & 2 & 0 & 0 & 0 & 11 & 0 \\
\hline $4 \mathrm{yr}$ & - & - & - & - & 1 & 0 & 2 & 0 & 0 & 0 & 3 & 0 \\
\hline$\geq 1 \mathrm{yr}$ & 11 & 0 & 12 & 0 & 1 & 0 & 0 & 1 & 0 & 0 & 24 & 1 \\
\hline$\geq 2 \mathrm{yr}$ & 3 & 1 & 8 & 0 & 6 & 0 & 1 & 0 & 0 & 0 & 18 & 1 \\
\hline$\geq 3 \mathrm{yr}$ & 1 & 0 & 1 & 0 & 10 & 0 & 5 & 2 & 0 & 1 & 17 & 3 \\
\hline Totals & 33 & 1 & 32 & 0 & 28 & 0 & 16 & 9 & 0 & 2 & 109 & 12 \\
\hline
\end{tabular}

a Adults whose year of birth was unknown were classified as $\geq 1 \mathrm{yr}$ of age in year banded

$\mathrm{M}$, males; F, females

131 helper-nest combinations). Regardless of how frequencies are measured, helping is performed primarily by males in this population.

Most helpers were males in part because the adult sex ratio was usually male-biased, averaging 56\% males between 1978 and 1984 (Curry 1987). Out of 472 helper-seasons involving birds of known sex, $64 \%$ of the birds that could have acted as helpers were males and $36 \%$ were females (Table 2), proportions similar to the population sex ratio. Males also helped disproportionately more often than females; $32 \%$ of the males with opportunities to help did so whereas only $7 \%$ of the females helped. This sex difference was not evident among juveniles, but arose later among adults because the proportion of birds helping varied with age among males but not among females (Table 2). Among females, incidence of helping was slightly higher for juveniles $(13 \%)$ than for adults $(5 \%)$, but the difference was insignificant, and the proportion of birds helping was consistently low among adult females of different ages. Among males, the incidence of helping was lower for juveniles $(16 \%)$ than for adults $(36 \% ; G=8.86$, d.f. $1, P<0.005$ ), but the proportion of birds helping did not vary significantly with age among adult males of known age. For both sexes, the incidence of helping was similar for adults of known age and of uncertain age. Most helpers were males, therefore, because males predominated in the population and because adult males had higher probability of helping than did females.

2. Helper-recipient relatedness. Kinship between potential helpers and recipient nestlings fell into eight categories, with coefficients of relatedness, $r$, ranging from 0.75 to 0 (Table 3). For further
Table 2. Incidence of helping in relation to age and sex of potential helpers. Values are percentages of birds that helped $(\mathrm{H})$ of those having the opportunity to do so; each bird is counted once for each pair it could have helped in a season $(n=$ number of helper-seasons)

\begin{tabular}{|c|c|c|c|c|c|}
\hline \multirow{3}{*}{$\begin{array}{l}\text { Age of potential } \\
\text { helper }\end{array}$} & \multicolumn{4}{|c|}{ Sex of potential helper } & \multirow[t]{3}{*}{$P^{a}$} \\
\hline & \multicolumn{2}{|c|}{ Female } & \multicolumn{2}{|l|}{ Male } & \\
\hline & $\% \mathrm{H}$ & $n$ & $\% \mathrm{H}$ & $n$ & \\
\hline Juvenile & $13 \%$ & 39 & $16 \%$ & 55 & NS \\
\hline $1 \mathrm{yr}$ & $6 \%$ & 31 & $25 \%$ & 40 & $*$ \\
\hline $2 \mathrm{yr}$ & $0 \%$ & 17 & $48 \%$ & 29 & $* * *$ \\
\hline$\geq 3 \mathrm{yr}^{b}$ & $0 \%$ & 7 & $36 \%$ & 33 & NS \\
\hline \multirow{2}{*}{ Other adults ${ }^{c}$} & $7 \%$ & 75 & $36 \%$ & 146 & $* * *$ \\
\hline & & $\overline{160}$ & & $\overline{302}$ & \\
\hline All ages & $7 \%$ & 169 & $32 \%$ & 303 & $* * *$ \\
\hline
\end{tabular}

analysis, all cases were pooled into three kinship categories, Close Relatives $(r \geq 0.5)$, Other Relatives $(0.38 \geq r \geq 0.12)$, and Nonrelatives. (None of the results were qualitatively different if the seven cases with $r=0.38$ are included as Close Relatives.) The relationship of a few potential helpers to one of the parents of the nestlings was unknown. I conducted analyses both excluding these birds and including them, making assumptions about their relationship to the breeders; tests for which these classifications made a difference are noted.

In terms of the proportion of birds that helped when they had opportunities to do so, mockingbirds differentially aided close kin. Omitting cases where relatedness was uncertain, $28 \%$ of 94 birds helped when potential recipients were 
Table 3. Incidence of helping (percentage of birds helping, $H$ ) in relation to relatedness. Each potential helper is counted once for each pair it could have helped in a breeding season ( $n=$ helper-seasons)

\begin{tabular}{|c|c|c|c|c|c|}
\hline $\begin{array}{l}\text { Relationship of breeders } \\
\text { to potential helper }\end{array}$ & $r^{\mathrm{a}}$ & $n$ & $\% \mathrm{H}$ & $\begin{array}{l}\text { Percentage } \\
\text { of tota } 1^{b}\end{array}$ & $\begin{array}{l}\text { Percentage } \\
\text { of helpers }\end{array}$ \\
\hline Both full siblings & 0.75 & 1 & $0 \%$ & $0.3 \%$ & $0 \%$ \\
\hline Parent $\times$ full sibling & 0.75 & 9 & $44 \%$ & $3.1 \%$ & $7.3 \%$ \\
\hline Both parents & 0.50 & 84 & $26 \%$ & $28.9 \%$ & $40.0 \%$ \\
\hline Parent $\times$ grandparent & 0.38 & 1 & $0 \%$ & $0.3 \%$ & $0 \%$ \\
\hline Parent $\times$ full sibling & 0.38 & 6 & $17 \%$ & $2.1 \%$ & $1.8 \%$ \\
\hline Parent $\times$ unknown & $0.25-0.5$ & 2 & $0 \%$ & $0.7 \%$ & $0 \%$ \\
\hline Offspring $\times$ unknown & $0.25-0.5$ & 4 & $0 \%$ & $1.4 \%$ & $0 \%$ \\
\hline Parent $\times$ nonrelative & 0.25 & 24 & $8 \%$ & $8.2 \%$ & $3.6 \%$ \\
\hline Full sibling $\times$ nonrelative & 0.25 & 5 & $0 \%$ & $1.7 \%$ & $0 \%$ \\
\hline Offspring $\times$ nonrelative & 0.25 & 9 & $33 \%$ & $3.1 \%$ & $5.5 \%$ \\
\hline Both grandparents & 0.25 & 1 & $0 \%$ & $0.3 \%$ & $0 \%$ \\
\hline Half sibling $\times$ nonrelative & 0.12 & 1 & $0 \%$ & $0.3 \%$ & $0 \%$ \\
\hline Nonrelative $\times$ unknown & $0-0.25$ & 37 & $22 \%$ & $12.7 \%$ & $14.5 \%$ \\
\hline Both nonrelatives & 0 & 107 & $14 \%$ & $36.8 \%$ & $27.3 \%$ \\
\hline
\end{tabular}

Close Relatives, compared with $13 \%$ of 47 birds with chances to help raise Other Relatives and 14\% of 107 birds that could have fed Nonrelative nestlings (Table 3; $G=7.52,2$ d.f., $P=0.02$ ). For this subset of cases, incidence of helping is significantly higher in the Close Relative category than in either of the latter two, which do not differ. Variation in incidence of helping among the three categories is also significant $(P \leq 0.03)$ if potential helpers of uncertain relationship are included, regardless of whether all such birds are all assumed to be minimally $(r=0)$ or maximally $(r=0.5)$ related to the breeder of unknown relationship. When minimal relatedness is assumed, the relationships among the three categories was unchanged, but if maximum relatedness is assumed, the proportions of birds helping both Close Relatives and Other Relatives were significantly greater than among those interacting with Nonrelatives.

3. Sex, age, and relatedness. Variation in incidence of helping with relatedness was independent of the lower overall incidence of helping by adult females. Kinship with potential recipients was similar for males and for females. Assuming minimal relatedness for cases where relationships were uncertain, and including potential helpers of all ages, $28 \%$ of males had opportunities to raise Close Relatives, $22 \%$ to raise Other Relatives, and $50 \%$ to raise Nonrelatives ( $n=166$ helper-seasons); for females, the respective percentages were $30 \%, 14 \%$, and
$55 \%(n=112$; Table $4 ; G=2.44,2$ d.f., NS). The distribution of potential recipients among relatedness categories did not differ between male and female potential helpers within any age class. Both sexes helped raise their Close Relatives most often (Table 4). Among males, incidence of helping varied significantly with relatedness for juveniles, yearlings, older birds of known age, and for males of all ages combined. Incidence of helping also varied with relatedness for females of all ages combined - more helped when potential recipients were Close Relatives - but among age classes the pattern was statistically significant only for females aged one year.

The higher incidence of helping among birds with chances to raise close kin was also independent of associations between helping and age, and between age and relatedness. The proportion of nestlings available to be helped that were Close Relatives declined with increasing age of potential helpers (Table 4). Of the nests available for juvenile male potential helpers, $58 \%$ contained Close Relatives, but for males two or more years old only $8 \%$ of the nests available contained Close Relatives $(G=38.0,4$ d.f., $P<0.001$ ). The pattern was similar for female potential helpers $(G=26.4,4$ d.f., $P<0.001)$. However, the relationship between age and relatedness fails to explain higher incidence of helping relatives because for both sexes proportionally more birds helped at nests containing relatives within most age classes (Table 4). Further- 
Table 4. Influence of age, sex, and relatedness on percentage of birds helping $(\mathrm{H})$. Each bird of known age is counted once for each pair it could have helped in a breeding season ( $n=$ helper-seasons)

\begin{tabular}{|c|c|c|c|c|c|c|}
\hline \multirow[t]{2}{*}{$r^{\mathrm{b}}$} & \multicolumn{2}{|c|}{ Males } & \multicolumn{2}{|c|}{ Females } & \multicolumn{2}{|c|}{ Total $^{a}$} \\
\hline & $\% \mathrm{H}$ & $n$ & $\% \mathrm{H}$ & $n$ & $\% \mathrm{H}$ & $n$ \\
\hline \multicolumn{7}{|l|}{ Juveniles } \\
\hline$r \geq 0.5$ & $28 \%$ & 32 & $16 \%$ & 25 & $20 \%$ & 70 \\
\hline $0.38 \geq r \geq 0.12$ & $0 \%$ & 12 & $17 \%$ & 6 & $6 \%$ & 18 \\
\hline$r \approx 0$ & $0 \%$ & 11 & $0 \%$ & 8 & $0 \%$ & 19 \\
\hline$P^{\mathrm{c}}$ & \multicolumn{2}{|c|}{$*$} & \multicolumn{2}{|c|}{ NS } & & $*$ \\
\hline \multicolumn{7}{|l|}{$1 \mathrm{yr}$} \\
\hline$r \geq 0.5$ & $60 \%$ & 10 & $29 \%$ & 7 & $44 \%$ & 18 \\
\hline $0.38 \geq r \geq 0.12$ & $0 \%$ & 8 & $0 \%$ & 3 & $0 \%$ & 11 \\
\hline$r \approx 0$ & $15 \%$ & 20 & $0 \%$ & 20 & $8 \%$ & 40 \\
\hline$P$ & \multicolumn{2}{|c|}{$* *$} & \multicolumn{2}{|c|}{$*$} & \multicolumn{2}{|c|}{$* * *$} \\
\hline \multicolumn{7}{|l|}{$\geq 2 \mathrm{yr}$} \\
\hline$r \geq 0.5$ & $100 \%$ & 4 & $0 \%$ & 2 & $67 \%$ & 6 \\
\hline $0.38 \geq r \geq 0.12$ & $20 \%$ & 10 & $0 \%$ & 2 & $17 \%$ & 12 \\
\hline$r \approx 0$ & $38 \%$ & 34 & $0 \%$ & 15 & $27 \%$ & 49 \\
\hline$P$ & \multicolumn{2}{|c|}{$*$} & \multicolumn{2}{|c|}{ NS } & \multicolumn{2}{|c|}{$(*)$} \\
\hline \multicolumn{7}{|l|}{ All ages } \\
\hline$r \geq 0.5$ & $41 \%$ & 46 & $18 \%$ & 34 & $28 \%$ & 94 \\
\hline $0.38 \geq r \geq 0.12$ & $11 \%$ & 37 & $12 \%$ & 16 & $11 \%$ & 53 \\
\hline$r \approx 0$ & $25 \%$ & 83 & $3 \%$ & 62 & $16 \%$ & 145 \\
\hline$P$ & * & & $*$ & $*$ & & \\
\hline
\end{tabular}

a Includes birds of unknown sex

${ }^{b}$ Estimated minimum relatedness between potential helper and nestlings

c $G$ - or Chi-square test of independence; $\left({ }^{*}\right) 0.05<P<0.1$,

$* P<0.05,{ }^{*} P<0.01,{ }^{* * *} P<0.005$

more, the incidence of helping increased somewhat with age among males, and did not vary with age among females (above). In a three-way test of association, with potential helpers classified as juveniles, yearlings, or older, and potential recipients as either close relatives $(r \geq 0.5)$ or not close relatives $(r \leq 0.38)$, age, relatedness, and helping were all associated with each other ( $G$-test, $P<0.005$ for each pairwise term). Therefore the incidence of helping varied with relatedness independently of age, even though fewer close relatives were available as potential recipients for older helpers and the incidence of helping varied with age.

Relatedness between potential helpers and recipients declined with age primarily because as a potential helper's parents died, more pairs available to be helped included birds not known to be relatives. Some such pairs included unrelated immigrant females, but others may have included distant relatives that had lived in the same group as the potential helper's parents, but for which evidence of kinship with older potential helpers was lacking. Undetected relationships of this kind may in part account for the high incidence of helping $(38 \%)$ by males two or more years old at nests containing birds classified as nonrelatives: older males whose parents had died may have helped pairs that in reality included relatives.

4. Influence of breeding status. Association between relatedness and helping was also independent of variation in the incidence of helping with breeding status. Both male and female mockingbirds are capable of breeding during the first year after fledging (Kinnaird and Grant 1982; Curry 1987). Because males outnumbered females and matings were monogamous, proportionally fewer female $(22 \%, n=125)$ than male $(44 \%, n=231)$ adult potential helpers were nonbreeders. As few female breeders $(7 \%)$ as nonbreeders $(9 \%)$ helped, but among males the incidence of helping varied with breeding status: $39 \%$ of nonbreeders but only $25 \%$ of breeders helped ( $G=4.61,1$ d.f., $P<0.05$ ). At least for males, these relationships could influence the association between helping and relatedness if birds were less likely to breed, and to become helpers, when close relatives were breeding. However, breeding status of potential helpers was not associated with relatedness to available recipients: of 14 adult males with opportunities to feed Close Relatives, $38 \%$ were breeders, compared with $48 \%$ of 25 potential helpers of Other Relatives, and $41 \%$ of 71 males with chances to feed nestlings classified as Nonrelatives ( $G=0.63,2$ d.f., NS).

The incidence of helping by breeders was additionally influenced by the success of their own breeding attempts. I defined breeders producing one or more fledglings as successful. Only 14\% of 36 males helped when their breeding was successful but $44 \%$ helped if their own breeding failed $(n=45 ; G=9.07,1$ d.f., $P<0.005)$. In contrast, $9 \%$ of 43 successful females helped compared to only $3 \%$ of 38 unsuccessful females; though statistically insignificant, the trend is in the opposite direction to the pattern among males.

\section{Mechanism for differential treatment of kin}

The observation that incidence of helping varies with helper-nestling relatedness raises the question of how mockingbirds direct their aid differentially to close relatives. Preference for kin by helpers could result from a mechanism based on associative learning, phenotype matching, recognition of genetic markers, or spatial distribution of alternative recipients (Holmes and Sherman 1983).

In the Genovesa mockingbird population, a mechanism based on association seems to operate. Mockingbird nestlings are fed by their parents and by helpers that are usually close relatives. There- 
Table 5. Influence of past association on the incidence of helping. Potential helpers are included if the identities of the birds that raised them were known; each is counted once for each pair it could have helped during a breeding season $(n=$ helperseasons)

\begin{tabular}{|c|c|c|c|c|c|c|c|}
\hline \multirow{3}{*}{$\begin{array}{l}\text { Age of } \\
\text { Potential } \\
\text { helper }\end{array}$} & \multicolumn{6}{|c|}{$\begin{array}{l}\text { Number of breeders that fed potential } \\
\text { helper in the nest }\end{array}$} & \multirow[t]{3}{*}{$P^{a}$} \\
\hline & \multicolumn{2}{|l|}{ Both } & \multicolumn{2}{|l|}{ One } & \multicolumn{2}{|c|}{ Neither } & \\
\hline & $\% \mathrm{H}$ & $n$ & $\% \mathrm{H}$ & $n$ & $\% \mathrm{H}$ & $n$ & \\
\hline Juveniles & $21 \%$ & 72 & $0 \%$ & 11 & $0 \%$ & 22 & $*$ \\
\hline Adults & $58 \%$ & 24 & $23 \%$ & 22 & $9 \%$ & 82 & $* * *$ \\
\hline All & $30 \%$ & 96 & $15 \%$ & 33 & $7 \%$ & 104 & $* * *$ \\
\hline
\end{tabular}

" $G$ - or Chi-square test of independence: ${ }^{*} P<0.05$, *** $P<$ 0.005

fore a bird that helped at a nest belonging to breeders that had fed the helper when it was a nestling would tend to direct its aid differentially to its relatives. To determine whether such a mechanism accounts for patterns of helping, I examined the incidence of helping by birds that were known to have been fed or not fed as nestlings by breeders with nests available to the potential helper. I predicted that more birds would help when given opportunities to feed nestlings belonging to breeders that had fed the helper as a nestling than when given chances to feed at nests belonging to breeders that did not participate in raising the helper. As predicted by the hypothesis that helping is influenced by association, the incidence of helping varied in relation to the prior behavior of breeders (Table 5). Among both adults and juveniles, proportionally more birds helped at nests where both breeders had fed the potential helper as a nestling than where one or both breeders had not. Larger samples would be required to determine whether relatedness or prior feeding behavior of breeders best predicts helping behavior, but the latter may be the most important determinant of helping in this population: $56 \%$ of 9 birds helped raise Nonrelatives when one or both breeders had fed the potential helper as a nestling, a higher incidence of helping than the $10 \%$ of 71 birds helping when given the opportunity to assist two unrelated breeders that were not prior feeders $(G=8.46$, 1 d.f., $P<0.005$ ) - and more than the $0 \%$ of 6 birds with chances to feed related nestlings $(r \geq 0.12)$ neither of whose parents were prior feeders (Fisher's Exact $P=0.042$, one-tailed).

Phenotype matching and marker recognition cannot be assessed critically in an observational study of this kind, but one observation suggests that mockingbird helpers do not discriminate among nestlings on the basis of their appearance. Four nestlings (all 7-8 days old) from each of two nests in adjacent territories were swapped for $1 \mathrm{~h}$; each nest was watched for $1 \mathrm{~h}$ before, during, and after the swap. Neither breeders nor helpers changed their behavior during this experiment: natural nestlings in each nest were fed by two breeders and a helper before and after the swap, and in both territories the same three adults fed foreign nestlings during the experiment. Mockingbirds therefore seem incapable of recognizing individual nestlings in the middle of the nestling period. Preferences for helping to raise relatives are therefore probably based, during the nestling period, on the identity of the breeders, not of the nestlings themselves.

I found no evidence to suggest that kin-directed helping was attributable to the way different available recipients were distributed spatially. Each resident used its entire group territory for foraging, most participated in territorial displays against neighbors on all sides, and each bird interacted frequently with all other group members. Most birds, including those classified as non-helpers, were observed near each nest in their territory, suggesting that each bird knew the location of every nest in its group. Pairs frequently nested in opposite ends of their group territory in successive years, and relative nesting locations of pairs within the territory were often reversed, so spatial separation of nests was not sufficiently consistent to serve as a basis for discrimination of kin. Furthermore, fledglings from different nests mixed freely throughout the group territory. Since fledglings were not fed by non-helpers (see Methods), the helpers (and parents) must have learned which fledglings to feed during the late nestling period based on associations at the nest. Recognition based on location within the territory would produce more errors than were observed.

\section{Choices among potential recipients}

A critical test of whether help is directed preferentially toward kin is if birds help feed most closely related nestlings when given a choice among two or more nests. Juvenile mockingbirds did exhibit such preferences. Considering only those juveniles known to have helped, eight could have helped at the nests of two simultaneously breeding pairs. All eight fed full siblings in one nest and did not feed more distantly related nestlings in the other nest (Binomial test, $P<0.01$ ). I was unable to carry out this test for adult helpers because relationships 


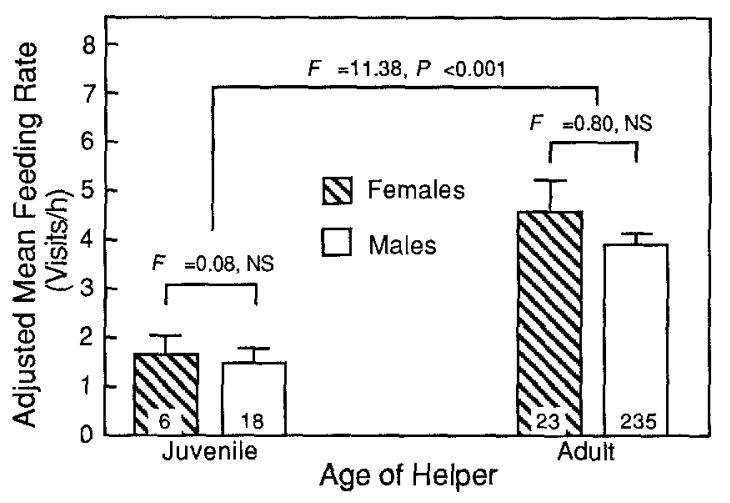

Fig. 1. Effect of helper age and sex on helper feeding rates. Heights of bars indicate adjusted mean number of feeding visits/ $\mathrm{h}( \pm \mathrm{SE})$ from ANCOVA, with nestling age as covariate; numbers of nestwatches indicated inside bars. $F$ and $P$ values are for tests of equality of adjusted means between groups connected by brackets; where not noted, pairwise contrasts were not signifícant $(P>0.1)$

among all participants (a helper and the different sets of nestlings available to be fed) were known in only a few cases. Four adults helped at only one of two available nests, but all were equivalently related to both available broods. In three other cases, results were equivocal: two yearling males helped their parents in preference to feeding more distantly related offspring, but another adult male helped an unrelated pair when it could have helped its brother and an immigrant female.

\section{Variation in helping effort}

In a multiple regression analysis of helper feeding rates, treating the rate calculated for each helper in each nest-watch as an independent observation, feeding rates varied significantly with age of the chicks but not with time of day, year, or number of chicks. To statistically control for nestling age, I performed analyses of covariance for subsequent analyses of helper feeding rates, with days since first hatching as the covariate. In all analyses, the assumption of equal slopes of the regressions for each group was upheld.

Adjusted mean feeding rate varied with the age but not sex of the helper (Fig. 1). Juveniles fed nestlings at lower rates than did adult helpers. Age had no additional effect on feeding rates among adults; variation among mean rates for helpers known to be one, two, three, or more than three years of age was not significant $(F=0.87,3$ d.f., $P>0.4$ ). Sex of neither juvenile nor adult helpers affected feeding rate.

Because feeding rates did not vary with age or sex among adult helpers, I pooled all adults to test for the effect of relatedness on feeding rate.

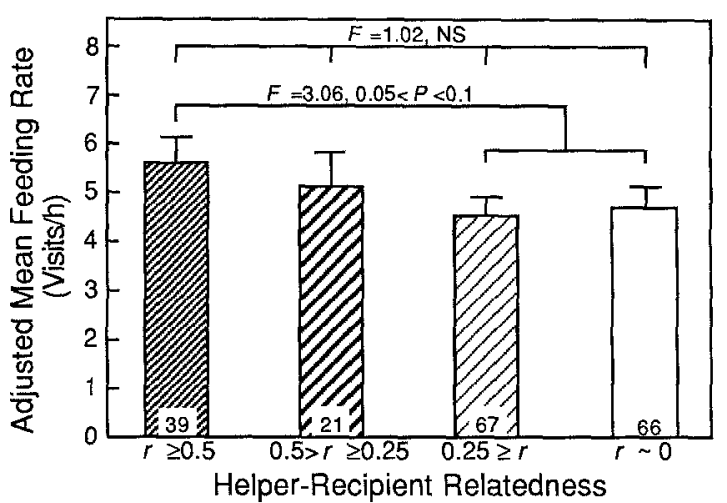

Fig. 2. Effect of relatedness between helpers and recipient nestlings on helper feeding rates. Format and tests as in Fig. 1. Cases where relatedness was uncertain but known to fall between 0.5 and 0.25 (see Table 3 ) are included in the category $0.5>r \geq 0.25$; cases where relatedness fell between 0.25 and 0 are included in the category $0.25 \geq r$

I excluded juveniles to remove a source of bias; juvenile helpers all fed closely related nestlings at low rates. I divided adult helpers into four relatedness categories (as in Table 3). Helper feeding rates did not vary significantly with relatedness among these four relatedness categories, but there was a trend suggesting that closely related helpers fed at higher rates than helpers in the two most distantly related categories combined ( $r \leq 0.25$; Fig. 2 ).

\section{Discussion}

The results of this study indicate that kinship has an important influence on helping behavior in $\mathrm{Ga}$ lápagos mockingbirds. The principal effect of kinship is on the incidence of helping: the probability that a bird acts as a helper varies with its relatedness to the potential recipients of its aid. Mockingbirds with opportunities to choose among different nests may also feed close relatives in preference to less closely related nestlings.

Incidence of helping that varies with relatedness has been reported for one mammalian cooperative breeder (Owens and Owens 1984). However, for territorial birds that breed cooperatively, variation in helping behavior as a function of kinship has not been demonstrated clearly in any previous study, and has been suggested in only two: both probability of helping and effort expended by helpers may vary with relatedness in the white-browed sparrow weaver (Plocepasser mahali; Lewis 1982a, b), but supporting data are scanty, and breeding long-tailed tits (Aegithalos caudatus) whose nests fail may become helpers only at nests of close relatives (Glen 1985). Variation in the incidence of 
helping as a function of relatedness can be detected only when birds do not help at all available nests in their groups, but such behavior has been reported in only a few other species. These include two, or possibly three, Cyanocorax jays ( $C$. sanblasianus, $C$. yucatanica, and C. melanocyanea; Raitt and Hardy 1976; Hardy 1976; Hardy et al. 1981), the chestnut-bellied starling (Spreo pulcher; Wilkinson 1982), the noisy miner (Manorina melanocephala; Dow 1979), and the gray-breasted jay (Aphelocoma ultramarina; Brown 1970, 1987; Brown and Brown 1981 b). Kinship was not known sufficiently well in any of these studies to determine if the birds that did not help differed in relatedness to nestlings from those that did. These species breed plurally, and in each some birds feed at only a subset of their group's nests, also raising the possibility that choices among alternative potential recipients could be based on relatedness.

In being more likely to help at nests containing close relatives than at those with more distantly related nestlings, Galápagos mockingbird helpers behave similarly to helpers in some colonial species. Potential helpers in a large colony can interact with many breeding pairs of differing degrees of relatedness, and in the pied kingfisher (Ceryle rudis), some birds ("primary' helpers) feed the offspring of one or both parents, and not other less closely related nestlings in the colony (Reyer 1984). In the white-fronted bee-eater (Merops bulockoides), helpers aid close relatives nesting amongst other unrelated pairs that are rarely assisted (Emlen and Wrege 1983, unpublished paper at XX Int. Ethol. Conf., Madison, Aug. 1987). In both the territorial mockingbirds and the colonial species, kin-directed helping probably cannot be attributed to the spatial arrangement of kin. This implies that some mechanism more subtle than spatial cues is responsible for determining which birds help and who receives their help. In the mockingbirds, association between helpers and breeders during the helper's development better accounts for the observed pattern of helping than does relatedness (Tables 4 and 5). Mockingbirds may remember which birds feed them, without distinguishing between parents and helpers (see also Brown and Brown 1980). The observation that helpers continued to feed foreign nestlings during the nestlingswap experiment also suggests that helpers respond more to the identity of the breeding pair than to the identity of the nestlings. The proximate cues that enable mockingbirds to remember which individuals raise them are, however, unknown.

Preferential treatment of relatives by helpers could also result if helpers aid any birds with whom they associate as members of the same social group, as long as group members are on average more closely related than members of the population chosen at random. Helping that follows such a 'membership' rule has not been ruled out for plurally-breeding gray-breasted jays (Brown and Brown 1980). Galápagos mockingbirds, however, do not simply aid other members of their groups in preference to birds in other groups, because the kin-preferential helping behavior I observed takes place within groups. In contrast, helpers in singularly-breeding species are typically the offspring of at least one of the group's breeders, so they can reliably restrict help to relatives by feeding nestlings in their natal territory (Rabenold 1985). Furthermore, potential helpers in singular-breeding systems have few options. Even if a change occurs among the breeders affecting relatedness, the potential helper has no other available recipients of its aid in the group. If helpers in singular groups can usually help close relatives either by following spatial cues (i.e. feeding at any nest in their territory) or by relying on social relationships (feeding the offspring of the group's breeders), more complex mechanisms such as one based on associative learning by nestlings would not be expected to have evolved (Hamilton 1964; Brown and Brown 1980; Holmes and Sherman 1983; Rabenold 1985).

In either singularly or plurally breeding species, some variation in helping behavior could arise if immigrants, unrelated to other birds in their new groups, helped less than birds remaining in their natal groups. This form of membership rule may be followed by white-browed sparrow-weavers (Lewis 1982b). Dispersal patterns have also been used to explain differences in helping tendencies between the sexes (Woolfenden and Fitzpatrick 1978; Stallcup and Woolfenden 1978). In the mockingbird population on Genovesa, females do disperse from their natal groups more frequently and farther than males (Curry 1987 and in prep.). This pattern in part explains why relatedness to potential recipients declines with age of potential helpers: as they age, more females join new groups made up of nonrelatives, and their positions in their former groups are filled by other females not related to the remaining males. In their new groups, immigrant females usually breed and rarely help raise available unrelated nestlings, so dispersal is involved in giving rise to the association between kinship and helping for females. In contrast, nearly all males remain in their natal groups. Their helping behavior is influenced by whether the female breeder available to be helped is an un- 
related immigrant, or a related female present in the group when the potential helper was born.

Kinship does not influence the effort, as measured by feeding rates, expended by those mockingbirds that help. Rabenold (1985) and Payne et al. (1985) obtained similar negative results. Correlations between relatedness and effort by helpers have been reported in only two studies. Primary pied kingfisher helpers, which feed related nestlings, invest more energy than secondary helpers, which usually feed unrelated nestlings (Reyer 1984). However, since these two types of helpers also seem to gain benefits from helping through different routes, comparison of their investment may not be a meaningful test of the influence of relatedness. Clarke (1984) reported that bell miners varied feeding rates in relation to relatedness, but as noted by Payne et al. (1985) and Brown (1987), Clarke's analysis was flawed by the inclusion of parents feeding their own young. The lack of a relationship between relatedness and investment by mockingbird helpers is not surprising, because animals are expected to distribute aid in proportion to relatedness only when restrictive conditions of diminishing returns hold (Altmann 1979; Weigel 1981).

Even if helpers receive direct benefits from helping, the results of this study, demonstrating a relationship between kinship and helping behavior, would be expected only if indirect fitness benefits are important. A helper could gain directly by receiving reciprocated help when breeding either from the breeders it assisted or from the individuals it fed in the nest (Ligon and Ligon 1978, 1983; Brown and Brown 1980; Emlen 1981, 1984; Ligon 1983; Wiley and Rabenold 1984). In the Genovesa population, though, helpers rarely recieve help from either the breeders they assist or the nestlings they feed (Curry 1987). Even if the benefits from such reciprocation had important effects on the lifetime reproductive success of helpers, it would still be advantageous under most circumstances to help close relatives because the cost of helping will be lower if the recipient fails to reciprocate, and because relatives may be less likely to cheat by not reciprocating (Trivers 1971; Alexander 1974, 1979; West Eberhard 1975; Rothstein 1980; Axelrod and Hamilton 1981). Preferential choice of kin as recipients of aid will be further favored if reciprocal interactions take place at the expense of other conspecifics (Wrangham 1982), as could occur in territorial cooperative breeders if reciprocity influenced competition for breeding vacancies. Helping may also confer direct fitness benefits if helpers gain eventually from the selfish behavior of the nestlings or breeders they aided (pseudoreciprocity; Connor 1986). Again preference for aiding kin would be advantageous because birds that aid nonrelatives gain nothing if they do not live to obtain the return benefit, or if the recipients are unlikely to survive to generate the benefit (Alexander 1974; Rubenstein 1982).

Once an associative mechanism for directing help toward kin arises, and if helpers were likely to receive reciprocated help from the birds they raise, it would become possible for the mechanism to be parasitized. By feeding unrelated nestlings, a helper could inveigle the nestlings into recognizing the helper as a close relative to which the nestlings will direct their help in the future. The importance of social bonds in determining which breeders a bird will assist when it becomes a potential helper has been discussed frequently (Brown and Brown 1980; Ligon 1983; Emlen 1984; Reyer 1984). However, the possibility that a helper could parasitize an associative kin-discrimination mechanism in order to deceive nestlings into later treating the helper as a relative has not been suggested previously, though the concept was developed in general terms by Trivers (1971). The hypothesis that some birds help in an attempt to 'parasitize' an established kin-discrimination mechanism generates the prediction that in any system where most birds preferentially assist birds that they recognize as relatives based on social relationships, some deceptive helping by nonrelatives can be expected to occur. Therefore, finding that a minority of helpers are unrelated to recipients is, contrary to the opinions of some workers (e.g. Ligon 1983), weak evidence against the importance of kinship as a determinant of helping (R.L. Curry and R.C. Connor, in prep.).

Helping behavior by Galápagos mockingbirds that is directed preferentially to close kin suggests that their cooperative behavior is influenced by effects on the indirect component of inclusive fitness. To reach a more complete understanding of the origin and maintenance of helping behavior, the relative importance of both direct and indirect benefits and costs of helping behavior must be considered. Such an analysis for Galápagos mockingbirds (Curry 1987 and in prep.) indicates that indirect benefits are small, but direct benefits are not detectable for most helpers. The preferential treatment of relatives demonstrated in this study indicates that kinship is an important determinant, and not an incidental correlate, of helping behavior in this population. The ability of most mockingbird helpers to direct their aid differentially toward close relatives both results from and contributes 
to the social complexity that is inherent in the species' plural breeding system.

Acknowledgements. Permission for this study was granted by the Dirección Nacional Forestal, Quito, the Galápagos National Park Service and the Charles Darwin Research Station. My research was conducted in conjunction with P.R. Grant's studies of Galápagos landbirds; I thank him for guidance, support, and criticism. I also thank the following individuals and institutions for their contributions: R.D. Alexander, J.L. Brown, A.W. Goldizen, W.G. Holmes, R.B. Payne, S. Sloane, R.W. Wrangham, and an anonymous reviewer for comments on the manuscript; D.J. Anderson, C.B. Chappel, N. Grant, S.A. Harcourt, M. Iturralde, and S.H. Stoleson for field assistance; M.F. Kinnaird for providing unpublished data; the Frank M. Chapman Fund, Sigma Xi-the Scientific Research Society, The University of Michigan, and the World Wildlife Fund-U.S. for financial support; and S.H. Curry for assistance and support throughout the research.

\section{References}

Alexander RD (1974) The evolution of social behavior. Annu Rev Ecol Syst 5:325-383

Alexander RD (1979) Darwinism and human affairs. University of Washington Press, Seattle, Wash

Altmann SA (1979) Altruistic behaviour: the fallacy of kin deployment. Anim Behav 27:958-959

Axelrod R, Hamilton WD (1981) The evolution of cooperation. Science 211:1390-1396

Brown JL (1970) Cooperative breeding and altruistic behaviour in the Mexican jay, Aphelocoma ultramarina. Anim Behav $18: 366-378$

Brown JL (1974) Alternate routes to sociality in jays-with a theory for the evolution of altruism and communal breeding. Am Zool 14:63-80

Brown JL (1978) Avian communal breeding systems. Ann Rev Ecol Syst 9:123-155

Brown JL (1980) Fitness in complex avian social systems. In Markl H (ed) Evolution of social behavior: hypotheses and empirical tests. Verlag Chemie, Weinheim, pp 115-128

Brown JL (1983) Cooperation - a biologist's dilemma. Adv Stud Behav 13:115-128

Brown JL (1987) Helping and communal breeding in birds Princeton University Press, Princeton, NJ

Brown JL, Brown ER (1980) Reciprocal aid-giving in a communal bird. Z Tierpsychol 53:313-324

Brown JL, Brown ER (1981 a) Kin selection and individual selection in babblers. In: Alexander RD, Tinkle DW (eds) Natural selection and social behavior. Chiron, New York, pp 244-256

Brown JL, Brown ER (1981 b) Extended family system in a communal bird. Science 211:959-960

Brown JL, Brown ER, Brown SD, Dow DD (1982) Helpers effects of experimental removal on reproductive success Science 215:421-422

Byers JA, Bekoff M (1986) What does "kin recognition " mean? Ethology $72: 342-345$

Caraco T, Brown JL (1986) A game between communal breeders: when is food-sharing stable? $\mathrm{J}$ Theor Biol 118:379-393

Clarke MF (1984) Co-operative breeding by the Australian bell miner Manorina melanophys Latham: a test of kin selection theory. Behav Ecol Sociobiol 14:137-146

Connor RC (1986) Pseudo-reciprocity: investing in mutualism Anim Behav 34:1562-1566

Curry RL (1985) Breeding and survival of Galápagos mock- ingbirds during El Niño. In: Robinson $G$, del Pino $E$ (eds) El Niño en las islas Galápagos: El evento de 1982-1983. Fundación Charles Darwin para las Islas Galápagos, Quito, pp 449-471

Curry RL (1987) Evolution and ecology of cooperative breeding in Galápagos mockingbirds (Nesomimus spp.). Ph D thesis, University of Michigan, Ann Arbor

Curry RL (1988) Group structure, within-group conflict and reproductive tactics in cooperatively breeding Galápagos mockingbirds. Anim Behav (in press)

Dow DD (1979) The influence of nests on the social behaviour of males in Manorina melanocephala, a communaily breeding honeyeater. Emu 79:71-83

Emlen ST (1978) The evolution of cooperative breeding in birds. In: Krebs JR, Davies NB (eds) Behavioural ecology. Sinauer, Sunderland, Mass, pp 245-281

Emlen ST (1981) Altruism, kinship, and reciprocity in the white-fronted bee-eater. In: Alexander RD, Tinkle DW (eds) Natural selection and social behavior. Chiron, New York, pp 217-230

Emlen ST (1984) Cooperative breeding in birds and mammals. In: Krebs JR, Davies NB (eds) Behavioural ecology, 2nd edn. Sinauer, Sunderland, Mass, pp 245-281

Emlen ST, Wrege PH (1983) The distribution of helping among kin in bee-eaters. Abstract, 101st Meeting Am Ornithol Union, New York

Glen NW (1985) The co-operative breeding behaviour of the long-tailed tit (Aegithalos caudatus). D Phil thesis, Oxford University, Oxford

Grant PR, Grant BR (1980) The breeding and feeding characteristics of Darwin's finches on Isla Genovesa, Galápagos. Ecol Monogr 50:381-410

Grant PR, Grant N (1979) Breeding and feeding of Galápagos mockingbirds. Nesomimus parvulus. Auk 96:723-736

Hamilton WD (1964) The genetical evolution of social behaviour, I and II. J Theor Biol 7:1-52

Hardy JW (1976) Comparative breeding behavior and ecology of the bushy-crested and Nelson San Blas jays. Wilson Bull $88: 96-120$

Hardy JW, Webber TA, Raitt RJ (1981) Communal social biology of the southern San Blas jay. Bull Florida State Mus; Biol Sci 26:203-264

Harvey PH (ed) (1980) Mechanisms of kin-correlated behavior group report. In: Markl H (ed) Evolution of social behavior: hypotheses and empirical tests. Verlag Chemie, Weinheim, pp 183-202

Holmes WG, Sherman PW (1983) Kin recognition in animals. Am Scient 71:46-55

Kinnaird MF, Grant PR (1982) Cooperative breeding by the Galápagos mockingbird, Nesomimus parvulus. Behav Ecol Sociobiol 10:65-73

Lewis DM (1982a) Cooperative breeding in a population of white-browed sparrow weavers Plocepasser mahali. Ibis $124: 511-522$

Lewis DM (1982b) Dispersal in a population of white-browed sparrow weavers. Condor 84:306-312

Ligon JD (1983) Cooperation and reciprocity in avian social systems. Am Nat $121: 366-384$

Ligon JD, Ligon SH (1978) Communal breeding in green woodhoopoes as a case for reciprocity. Nature 276:496-498

Ligon JD, Ligon SH (1983) Reciprocity in the green woodhoopoe (Phoeniculus purpureus). Anim Behav 31:480-489

Maynard Smith I (1964) Group selection and kin selection. Nature 201:1145-1146

Owens DD, Owens MJ (1984) Helping behaviour in brown hyenas. Nature 308:843-845

Payne RB, Payne LL, Rowley I (1985) Splendid wren Malurus 
splendens response to cuckoos: an experimental test of social organization in a communal bird. Behaviour 94:108-127

Rabenold KN (1984) Cooperative enhancement of reproductive success in tropical wren societies. Ecology 65:871-885

Rabenold KN (1985) Cooperation in breeding by nonreproductive wrens: kinship, reciprocity, and demography. Behav Ecol Sociobiol 17:1-17

Raitt RJ, Hardy JW (1976) Behavioral ecology of the Yucatan jay. Wilson Bull 88:529-554

Reyer H-U (1980) Flexible helper structure as an ecological adaptation in the pied kingfisher (Ceryle rudis rudis L.). Behav Ecol Sociobiol 6:219-227

Reyer H-U (1984) Investment and relatedness: a cost/benefit analysis of breeding and helping in the pied kingfisher ( $\mathrm{Cer}$ yle rudis). Anim Behav 32:1163-1178

Ricklefs RE (1975) The evolution of cooperative breeding in birds. Ibis 117:531-534

Rothstein SI (1980) Reciprocal altruism and kin selection are not clearly separable phenomena. J Theor Biol 87:255-261

Rowley I (1981) The communal way of life of the splendid wren, Malurus splendens. Z Tierpsychol 55:228-267

Rubenstein DI (1982) Risk, uncertainty and evolutionary strategies. In: King's College Sociobiology Group (eds) Current problems in sociobiology. Cambridge University Press, Cambridge, pp 91-111

Sokal RR, Rohlf FJ (1981) Biometry, 2nd edn. Freeman, San Francisco
Stallcup JA, Woolfenden GE (1978) Family status and contributions to breeding by Florida scrub jays. Anim Behav 26:1144-1156

Trivers RL (1971) The evolution of reciprocal altruism. Q Rev Biol 46:35-57

Vehrencamp SL (1979) The roles of individual, kin, and group selection in the evolution of sociality. In: Marler P, Vandenbergh $\mathbf{J}$ (eds) Handbook of behavioral neurobiology, vol. 3 , pp 351-394. Plenum, New York

Weigel RM (1981) The distribution of altruism among kin: a mathematical model. Am Nat 118:191-201

West Eberhard MJ (1975) The evolution of social behavior by kin selection. Q Rev Biol 50:1-33

Wiley HR, Rabenold KN (1984) The evolution of cooperative breeding by delayed reciprocity and queuing for favorable social positions. Evolution 38:609-621

Wilkinson R (1982) Social organization and communal breeding in the chestnut-bellied starling (Spreo pulcher). Anim Behav 30:1118-1128

Woolfenden GE, Fitzpatrick JW (1978) The inheritance of territory in group-breeding birds. Bio Science 28:104-108

Woolfenden GE, Fitzpatrick JW (1984) The Florida scrub jay. Princeton University Press, Princeton, NJ

Wrangham RW (1982) Mutualism, kinship, and social evolution. In: King's College Sociobiology Group (eds) Current problems in sociobiology. Cambridge University Press, Cambridge, pp 269-289 